\title{
EFECTO DE CAMBIOS EN MANEJO POSCOSECHA SOBRE LA CALIDAD Y VIDA ÚTIL DEL CULANTRO COYOTE PARA EXPORTACIÓN (Eryngium foedium L.)
}

\author{
María del Milagro Cerdas Araya ${ }^{1 / *}$, Marta Montero Calderón ${ }^{*}$ \\ Palabras clave: Culantro coyote; manejo poscosecha; lavado; daño mecánico; almacenamiento; vida útil. \\ Keywords: Cilantro coyote; postharvest handling; washing; mechanical damage; storage; shelf life.
}

\begin{abstract}
RESUMEN
Se determinó el efecto de varias modificaciones en prácticas poscosecha del culantro coyote para exportación: sacudido manual de los rollos de culantro; sustitución de bandas de hule por gazas plásticas; uso del tensoactivo

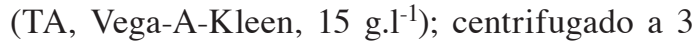
velocidades; 2 materiales de empaque; y 3 temperaturas de almacenamiento, sobre la mejora de los procesos y la calidad del culantro. El sacudido manual de rollos amarrados con ligas provocó más daños mecánicos (87\%) que sin amarre (63\%). El uso del TA permitió hasta 30\% más eliminación de agua durante 5 minutos de escurrido pasivo y facilitó la recuperación de insectos respecto al lavado con agua (37 vs 19 / rollo) y este efecto fue mayor al combinarlo con el sacudido (56 y 48 /rollo, resp.). El escurrido con centrífuga manual aceleró el drenaje del exceso de agua, de $33 \mathrm{ml} / 100 \mathrm{~g}$ a $25 \mathrm{rpm}$, a 84 $\mathrm{ml} / 100 \mathrm{~g} 50$ y $75 \mathrm{rpm}$ durante el primer minuto, con escasa remoción adicional de agua a tiempos mayores (2-5 min). Los daños mecánicos fueron 15 y $20 \%$ menores a 25 y $50 \mathrm{rpm}$, en contraste con $30 \%$ a $75 \mathrm{rpm}$. La sustitución de ligas por gazas plásticas para amarrar los rollos redujo los daños mecánicos de hojas en $11 \%$. El almacenamiento a $10^{\circ} \mathrm{C}$ permitió conservar
\end{abstract}

1 Autor para correspondencia. Correo electrónico: maria.cerdasaraya@ucr.ac.cr

\begin{abstract}
Effect of charges in post-harvest handling on the quality and shelf-life of coyote coriander (Eryngium foedium L.) for export. The effect several of changes in post-harvest practices of coyote coriander for export was determined: hand shaking of coriander tied and loose bunches; plastic loops instead of rubber bands to hold bunches together; a commercial surfactant (TA, Vega-AKleen, 15 g. $\mathrm{l}^{-1}$ ) incorporated in washing solution; 3 speeds of centrifugation; 2 packaging materials and 3 storage temperatures. Hand shaking of tied bunches increased mechanical damage to $87 \%$, in contrast with $63 \%$ for untied bunches. The use of the surfactant increased up to $30 \%$ excess water elimination during the first 5 minutes of passive drainage, as compared with produce washed with pure water, and also lead to larger insect recovery (37/bunch with surfactant, and 19/ bunch without). When hand shaking was used after washing, insect extraction was larger (56 and 48/ bunch, respectively). Water drainage increased from 33 to $84 \mathrm{ml} / 100 \mathrm{~g}$ when centrifugation speed increased from 25 to 50 and $75 \mathrm{rpm}$ in the first minute, but no further changes were observed after additional timing (2-5 minutes) for $75 \mathrm{rpm}$; however, mechanical damages were 15 and $20 \%$ less at 25 and $50 \mathrm{rpm}$, in contrast with $30 \%$ at
\end{abstract}

\footnotetext{
* Universidad de Costa Rica, Centro de Investigaciones Agronómicas, Costa Rica.
} 
la calidad del producto por 15 días, con menos de $5 \%$ de amarillamiento y de $1 \%$ de daños por necrosis y Cercospora para los 2 tipos de empaque.
$75 \mathrm{rpm}$. As for substitution of rubber bands with plastic loops, the latter allowed $11 \%$ of mechanical damage reduction. Storage temperature at $10^{\circ} \mathrm{C}$ best preserved product quality, regardless of the packaging material, showing less than $5 \%$ of yellow leaves and less than $1 \%$ of necrosis and Cercospora damage symptoms after 15 days of storage.

\section{INTRODUCCIÓN}

El culantro coyote (Eryngium foetidum L.); de la familia apiáceae, es un cultivo que tradicionalmente se ha consumido en Costa Rica desde hace muchos años. En 1990 se realizó la primera exportación a Miami, Florida y en el año siguiente se dio el establecimiento de la primera planta de empaque en la zona Atlántica de Costa Rica (Alvarado y Villalobos 1999). En los últimos años, la actividad ha crecido y en zonas de Siquirres (Linda Vista, 52 millas, Santa Marta y Bajos del Tigre) y Turrialba (Tres Equis, Chitaría y Pilón de Azúcar) se ha convertido en una opción para exportar a mercados de Miami, Nueva York y Canadá, favoreciendo a más de 150 pequeños y medianos productores y sus familias (Colegio de Ingenieros Agrónomos 2003). La exportación de este producto tradicionalmente se ha hecho por vía aérea con un costo $80 \%$ más alto que el costo por vía marítima (D. Camacho. 2010. Comunicación personal exportador, Linda Vista de Siquirres) lo que reduce en gran medida la ganancia de los exportadores y productores nacionales. Según Mohammed y Wickham (1995) la vida útil del culantro a condiciones ambientales después de la cosecha es muy reducida, lo que es un inconveniente para su transporte y comercialización por períodos extensos. Después de 17 días a temperaturas entre $22^{\circ} \mathrm{C}$ y $28^{\circ} \mathrm{C}$ reportaron malos sabores y deshidratación.

Según estudios de respaldo de la Norma Codex de culantro coyote (Cerdas 2010), realizados en el Laboratorio de Tecnología Poscosecha (CIA, UCR) la calidad del culantro coyote se ve afectada por el lavado y sacudido de los rollos de culantro en la planta de empaque, ya que estos producen daños mecánicos en las hojas. La Norma Regional del CODEX para el culantro coyote (CODEX STAN 304R-2011) establece que las hojas quebradas o partidas no pueden exceder el $10 \%$ de las hojas del rollo o manojo de culantro. No obstante, la tendencia es que en las líneas de empaque, se realice un proceso de lavado de 3 etapas: 3 lavados con agua clorada (100 ppm de hipoclorito de sodio) y uno con agua, para eliminar el exceso de cloro y un sacudido manual que incrementan notablemente los daños en la lámina de la hoja, de 5 y $22 \%$ antes del proceso de lavado hasta entre 15 y $42 \%$ una vez que se completa el proceso de empaque (Cerdas 2010).

Costa Rica es pionero en la exportación de culantro coyote a los Estados Unidos y por ello el Ministerio de Agricultura y Ganadería (2012) publicó una guía para orientar al exportador con las regulaciones sanitarias y fitosanitarias de importación establecidas por los países de destino. Con la aprobación en el 2011 de la norma regional CODEX de Culantro Coyote, la calidad del culantro producido en el país será un factor determinante para mantener los mercados en Estados Unidos, con el nivel de competitividad que estos requieren.

El objetivo de esta investigación fue evaluar el efecto de las operaciones de lavado y preparación para el mercado fresco sobre la 
incidencia de daños mecánicos, retención de agua e insectos y la conservación de la calidad del culantro coyote fresco, así como el efecto de las condiciones de almacenamiento sobre la vida útil.

\section{MATERIALES Y MÉTODOS}

Se trabajaron con rollos amarrados con bandas de hule y manojos con hojas sueltas de culantro coyote (Eryngium foetidum L.) cosechados en la zona de Tres Equis de Turrialba en Cartago, Costa Rica y empacadas en la planta Linda Vista, pero sin recibir tratamientos de lavado ni de sacudido. Estos fueron llevados al Laboratorio de Tecnología Poscosecha del Centro de Investigaciones Agronómicas de la Universidad de Costa Rica el mismo día de la cosecha.

El estudio consistió de una serie de ensayos para evaluar el efecto sobre la calidad e integridad de las hojas de culantro coyote de varias prácticas poscosecha, alternativas a las utilizadas actualmente en la línea de empaque, según se detalla seguidamente. Los materiales utilizados se sometieron a un proceso de doble lavado con agua clorinada (100 ppm), seguido por uno con agua sin cloro, tal como se realiza en la planta de empaque.

\section{Efecto del sacudido manual y tipo de presentación del culantro coyote}

Se utilizaron 10 rollos de 100 hojas, la mitad de los cuales fueron amarrados en la base del tallo con bandas de hule (2 $\mathrm{mm}$ de diámetro y 2,3 cm de longitud), la otra mitad de los rollos no se amarró (100 hojas sueltas). Después del lavado, cada rollo se tomó por la base y se sacudió manualmente (rollos y hojas sueltas), sosteniendo los rollos o manojos por la base de las hojas elevándolos a 1,20 m de altura y sacudiendo rápidamente y con fuerza hacia abajo para remover el agua y posibles contaminantes, proceso que se realiza comercialmente en las plantas empacadoras. El testigo consistió en rollos traídos de campo sin sacudir con y sin banda de hule de los cuales se hizó una valoración inicial.
Se determinó la incidencia de hojas con daño mecánico para todos los tratamientos debido al sacudido o no de los mismos.

\section{Efecto del uso de un tensoactivo (TA) para facilitar el escurrido del agua de lavado del culantro coyote}

Se evaluó el uso de un TA para reducir la tensión superficial del agua sobre la superficie de las hojas del culantro y facilitar la salida de un mayor volumen del agua de lavado de los rollos de culantro, sin necesidad de sacudir el producto. Para ello el culantro en rollos amarrados con banda de hule fue sometido a una inmersión por $30 \mathrm{~s}$ en una solución con 15 g. $1^{-1}$ del tensoactivo Vega-A-Kleen (ECOLAB, SA) y se colocó sobre una superficie inclinada $\left(10^{\circ}\right)$ por $5 \mathrm{~min}$; se recolectó el agua drenada, la cual se reportó en $\mathrm{ml} / 100 \mathrm{~g}$ producto. El tratamiento testigo consistió en lavar los rollos amarrados en agua pura y luego proceder a medir de la misma forma el volumen de agua que drenó de los rollos.

\section{Efecto del centrifugado manual para facilitar la salida del agua de lavado y sobre la incidencia de daños mecánicos en el culantro coyote}

Se procedió al lavado comercial de los rollos de culantro, posteriormente se removió la liga de hule de los 5 rollos para acomodarlos en la centrífuga para vegetales de 5 gal (marca Dynamic, TIPS S.A., Costa Rica). Lo anterior con el fin de evaluar el efecto de la velocidad de la centrífuga manual sobre la salida de agua como método alternativo de salida de agua, así como el efecto de la misma sobre la incidencia de daños mecánicos en las hojas del culantro coyote, con velocidades de 25,50 y $75 \mathrm{rpm}$ por 5 minutos. Para cada velocidad, se recolectó el agua escurrida cada minuto y se reportó en $\mathrm{ml} / 100$ g culantro. Después de 5 minutos, se determinó la incidencia de hojas con daños mecánicos, ya fuera como \% de hojas quebradas o con otros daños mecánicos. 
Efecto de la inmersión en agua con o sin tensoactivo y el sacudido del culantro en rollos u hojas sueltas sobre la eliminación de insectos

Con la finalidad de facilitar la salida de insectos de los rollos de culantro, como alternativa al sacudido de estos, se evaluó la efectividad del uso del tensoactivo (TA) Vega-A-Kleen (ECOLAB, S.A.) a 15 g.l $^{-1}$, para remover los insectos del culantro en la presentación de rollos amarrados con banda de hule u hojas sueltas con y sin sacudir. Para ello se utilizaron rollos de $200 \mathrm{~g}$ de culantro, 5 de estos amarrados con banda de hule y 5 en hojas sueltas para cada tratamiento. Se sumergieron por $30 \mathrm{~s}$ en una solución de TA o en agua, posteriormente se sacudió o no, según el procedimiento descrito. Se realizaron 2 tipos de conteo, por inspección en el agua de lavado o por la agitación de las hojas lavadas y escurridas con o sin sacudido sobre una superficie blanca. El tratamiento testigo no fue lavado. Los resultados se presentaron como incidencia de insectos en el agua de inmersión y en la superficie de las hojas.

\section{Efecto del uso de gazas plásticas sobre la incidencia de daño mecánico en hojas de culantro coyote}

Se evaluó la sustitución de las bandas de hule por gazas plásticas $(0,5 \mathrm{~cm}$ x $20 \mathrm{~cm})$. Para ello se pidió al agricultor que cosechara el material equivalente a 10 rollos (100 hojas cada uno). Una vez en el laboratorio se procedió a tomar el material equivalente a 5 rollos y se les colocó la banda de hule tradicional, a la otra mitad se le colocó gazas plásticas, ambos sin ningún tratamiento de planta. Se dejaron al ambiente en bolsas de polietileno de baja densidad sin sellar $\left(20^{\circ} \mathrm{C}\right)$ por 3 días simulando el período de comercialización a EE.UU. Se evaluó la incidencia de hojas con daños mecánicos provocados por las bandas o por las gazas, según el tratamiento.

\section{Efecto de las condiciones de almacenamiento sobre el amarillamiento, necrosis-y}

Cercospora sp., en hojas de culantro

Se evaluó el efecto de las condiciones de almacenamiento mediante 2 materiales de empaque y 3 temperaturas de almacenamiento en rollos de culantro de 100 hojas. Se usaron bolsas transparentes de polietileno+nylon (Dow Chemical) (30 x $48 \mathrm{~cm})$, y de polipropileno (Plásticos S.C., Guadalupe, Costa Rica) (30 x 45 $\mathrm{cm})$ y temperaturas de 10,12 y $15^{\circ} \mathrm{C}$. En cada bolsa se empacó un rollo y ésta se cerró con una banda de hule. Se prepararon 5 repeticiones por empaque para cada una de las temperaturas, y se almacenaron por 20 días, evaluando cada 2 o 3 días la incidencia o número de hojas con síntomas de amarillamiento (coloración amarilla en el tejido foliar), de necrosis (tejido acuoso y descompuesto) y de Cercospora sp. (hongo que produce manchas de forma circular u ovalada, de color pardo con el centro blanco o gris y rodeadas de un halo amarillamiento, según fue descrito por Macnab et ál. 1983).

El diseño estadístico fue un diseño irrestricto al azar, con 5 repeticiones, excepto en la evaluación del efecto del uso de gazas plásticas en el cual se usaron 10 repeticiones. Según la variable a evaluar en algunos ensayos la unidad experimental fueron rollos de $100 \mathrm{~g}$, en otros rollos de 100 hojas y en uno se usó rollos de 200 g, según el tipo de variable a evaluar. El análisis estadístico de los datos se realizó mediante separación de medias con el programa INFOSTAT versión 2012 y la comparación de medias se hizo por medio de la prueba DMS y con un alfa de $0,05 \%$.

En el Cuadro 1 se muestra un resumen de tratamientos y variables de respuesta por ensayo. 
Cuadro 1. Resumen de tratamientos y variables de respuesta.

\begin{tabular}{|c|c|c|}
\hline Nombre del ensayo & Tratamiento & Variables de respuesta \\
\hline $\begin{array}{l}\text { Sacudido manual y tipo de } \\
\text { presentación }\end{array}$ & $\begin{array}{l}\text { Con y sin sacudido } \\
\text { Con y sin banda de hule } \\
\text { Testigo: sin sacudir/con y sin banda }\end{array}$ & $\%$ de hojas con daño mecánico \\
\hline TA & $\begin{array}{l}\text { Con TA a } 15 \text { g.l }{ }^{-1} \\
\text { Testigo lavado con agua pura }\end{array}$ & Agua drenada $\mathrm{mL} / 100 \mathrm{~g}$ \\
\hline Centrifugado manual & $\begin{array}{l}\text { Centrifugado manual a } 25,50 \text { y } \\
75 \mathrm{rpm} / 5 \text { minutos }\end{array}$ & $\begin{array}{l}\text { Agua drenada } \mathrm{mL} / 100 \mathrm{~g} \\
\% \text { hojas con daño mecánico }\end{array}$ \\
\hline TA+sacudido & $\begin{array}{l}\text { Con y } \sin \text { TA a } 15 \text { g. } .^{-1} \\
\text { Con y sin bandas de hule } \\
\text { Con y sin sacudido } \\
\text { Testigo: culantro no lavado }\end{array}$ & $\begin{array}{l}\text { Extracción de insectos del agua de lavado } \\
\text { Extracción de insectos de la superficie de } \\
\text { las hojas }\end{array}$ \\
\hline Gazas plásticas & $\begin{array}{l}\text { Amarre con gasa plástica } \\
\text { Testigo amarre con banda de hule (ligas) }\end{array}$ & $\%$ de hojas con daño mecánico \\
\hline Almacenamiento y empaques & $\begin{array}{l}\text { Polieliteno/nylon a } 10^{\circ} \mathrm{C}, 12^{\circ} \mathrm{C} \text { y } 15^{\circ} \mathrm{C} \\
\text { Polipropileno a } 10^{\circ} \mathrm{C}, 12^{\circ} \mathrm{C} \text { y } 15^{\circ} \mathrm{C}\end{array}$ & $\begin{array}{l}\% \text { hojas con amarillamiento } \\
\% \text { hojas con necrosis } \\
\% \text { de hojas con Cercospora }\end{array}$ \\
\hline
\end{tabular}

\section{RESULTADOS Y DISCUSIÓN}

\section{Efecto del sacudido manual y presentación del culantro coyote}

Con el fin de determinar el efecto del sacudido manual y el tipo de presentación sobre la incidencia de hojas con daño mecánico, se tomaron 10 rollos de culantro coyote, 5 con amarre de bandas de hule y 5 en rollos sin amarrar (hojas sueltas) y se procedió a tomarlos por la base y sacudirlos manualmente hacia arriba y hacia abajo. Cuando los rollos amarrados con banda de hule fueron sacudidos (Figura 1), se obtuvo la mayor cantidad $(\mathrm{p} \leq 0,05)$ de hojas con daños mecánicos $(87 \%)$ con respecto a la presentación en manojos o rollos de hojas sueltas (63\%) y ambas presentaciones sin sacudir presentaron valores de incidencia de $48 \%$ y $34 \%$ de hojas con

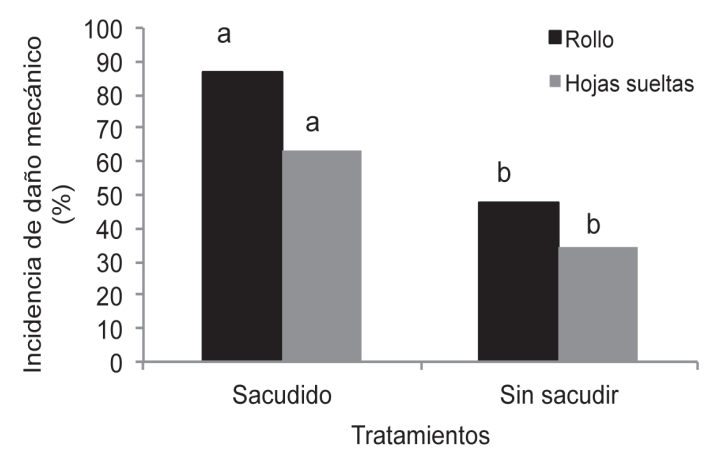

Medias del mismo tipo de presentación con diferente tratamiento con letras iguales no difieren entre sí según prueba DMS al $5 \%$.

Rollo: manojo de hojas amarrado con banda de hule. Hojas sueltas: manojo de hojas sin amarrar.

Fig. 1. Efecto del sacudido sobre la incidencia de daño mecánico en rollos y en hojas sueltas de culantro coyote. 
daños mecánicos respectivamente. Según Kays (1997), desde la cosecha hasta la comercialización de las hortalizas de hoja verde se producen un amplio rango de daños físicos que decrecen su valor comercial y los cuales a menudo acortan significamente su vida útil y señala que en una hortaliza de hoja como lo es la lechuga estos daños son aproximados al 5,8\% mientras que Cerdas (2010) encontró en estudios preliminares de culantro coyote entre 5\% y $42 \%$ de hojas dañadas desde cosecha hasta proceso de lavado en planta. Lo encontrado por el último autor puede deberse en gran medida a que durante el sacudido manual de los rollos hacia arriba, las hojas incrementan su velocidad rápidamente y se detienen súbitamente, con lo cual las hojas chocan entre sí y en el caso de los rollos amarrados con banda de hule, estos también chocan contra el amarre que las sostiene, lo que posiblemente hace que las hojas amarradas se quiebren con mayor facilidad, con respecto a los choques que puedan darse entre las hojas de los rollos sueltos y además la liga utilizada para formar los rollos, es delgada y al colocarla a presión, tiende a cortar las hojas, y con la agitación del sacudido, los daños tienden a llegar hasta las nervaduras de las hojas. Los resultados también sugieren que aunque al usar hojas sueltas, se logran reducir parcialmente los daños mecánicos en las hojas, el beneficio es pequeño en contraste con la incomodidad de manipular el producto como rollos o manojos de hojas sueltas, por lo que se sugirió el manejo del producto en rollos, pero con un amarre que proteja más el producto, en sustitución de las bandas de hule.

Por otro lado, aunque se determinó que el sacudido puede aumentar en más de 20 puntos porcentuales el número de hojas con daños mecánicos, el producto utilizado en este ensayo, mostró una alta incidencia, aún para producto sin sacudir, atribuido a las condiciones en que fue recibido en la planta empacadora, con niveles muy superiores a los permitidos por la normativa del CODEX para este producto, que corresponde al $10 \%$ de hojas quebradas o partidas en culantro de Categoría I y $20 \%$ en Categoría II.

\section{Efecto del uso de un tensoactivo (TA) sobre el escurrido del culantro coyote}

Para determinar el efecto de un TA sobre la salida de agua del rollo de culantro se evaluó el uso

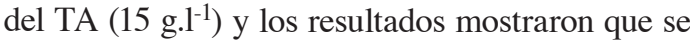
eliminó hasta un $30 \%$ más de volumen de agua con respecto a los rollos lavados con el tratamiento testigo o sea solo con agua (datos no mostrados). Por tanto el TA facilitó el drenaje del agua durante el escurrido por gravedad, al reducir la tensión superficial del líquido sobre la superficie de las hojas de los rollos de culantro con amarre. También se observó que se favoreció la remoción de suciedad y restos de plagas. El uso de tensoactivo con solo el escurrido por gravedad no fue suficiente para remover suficiente cantidad de agua, por lo que se consideró el uso de este agente en combinación con el sacudido manual o el centrifugado, que fueron evaluados en pruebas posteriores con lo cual se podrían reducir los esfuerzos mecánicos aplicados a los rollos y reducir los daños.

\section{Efecto del centrifugado manual sobre el escurrido y la incidencia de daños mecánicos en el culantro coyote}

Se evaluó el efecto del tiempo de centrifugado manual sobre la extracción de agua de los rollos de culantro y sobre la incidencia de daños para lo cual se accionó una centrífuga manualmente a diferentes velocidades. Durante el primer minuto (Figura 2) se logró extraer la mayor cantidad de agua, y que ésta fue mayor, cuando se utilizaron velocidades de 50 y 75 rpm (más de 80 $\mathrm{ml} / 100 \mathrm{~g}$ de culantro), en contraste con la centrifugada a $25 \mathrm{rpm}$, para la que se recuperaron solo 33 $\mathrm{ml} / 100 \mathrm{mg}$ durante ese primer minuto. Después de 2 minutos de centrifugado, la remoción de agua de los rollos fue muy baja, independientemente de la velocidad de agitación. Estos resultados señalan la conveniencia de usar al menos $50 \mathrm{rpm}$ por 1 o 2 min para mejorar la eficacia de la remoción del agua y a la vez, evitar mayores tiempos de centrifugado porque estos podrían favorecer la incidencia de daños en las hojas. 


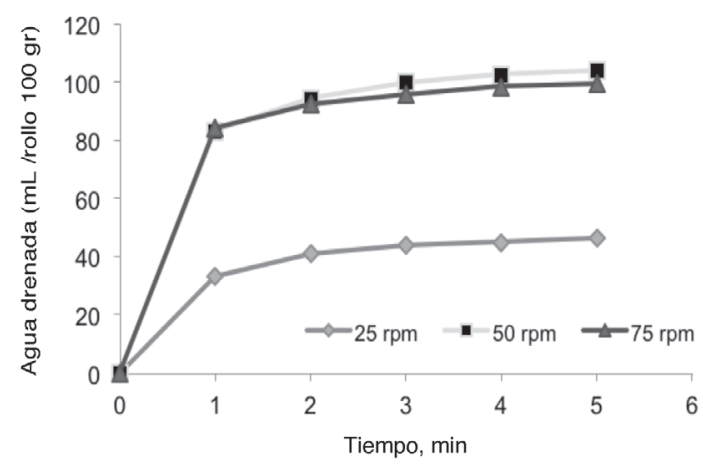

Fig. 2. Efecto de la velocidad de centrifugado sobre la extracción de agua de los rollos de culantro.

Con respecto al efecto de la velocidad del centrifugado sobre el número de hojas con daños mecánicos, se encontró que para 25 y 50 rpm, fueron significativamente menores y oscilaron entre 15 y $20 \%$, mientras que a $75 \mathrm{rpm}$ fueron del $30 \%$ (datos no mostrados), principalmente por quebraduras en la lámina foliar, lo cual sugiere que el escurrido con la centrífuga debe hacerse a velocidades inferiores de $75 \mathrm{rpm}$. Al igual que en las pruebas anteriores, el producto centrifugado a velocidades bajas, mostró incidencia de daños mecánicos cercanos a los máximos permitidos por la Norma Regional Codex para el Culantro Coyote (2011), que establece una tolerancia máxima de 10 y $20 \%$ para producto de categorías I y II, respectivamente, sugiriendo de nuevo la necesidad de revisar los procesos en el campo y la planta empacadora, para minimizar la incidencia de los daños mecánicos durante la manipulación del producto ya que según Singhal y Kulkarni (1998) muchas hojas de hortalizas son crujientes y se quiebran fácilmente cuando están húmedas debido a los lavados en plantas de empaque.

\section{Efecto de la inmersión en agua con o sin tensoactivo y el sacudido del culantro en rollos u hojas sueltas sobre la eliminación de insectos}

Para determinar el efecto del lavado con TA y del sacudido sobre la eliminación de insectos se procedió a lavar los rollos de culantro coyote con TA y con agua pura así como a sacudirlos manualmente. Las Figuras 3a y b muestran los resultados de la extracción de insectos de las hojas de culantro, recuperados en el agua de lavado (4a) o de las hojas después del lavado o sin lavar, para el caso del tratamiento testigo (4b) Se encontró, que al usar el tensoactivo, la cantidad de insectos recuperados en el agua de lavado, fue mayor (37 insectos) que cuando no se usó (19 insectos), independientemente de si el producto se sumergió en rollos o como hojas sueltas. La reducción de la tensión superficial del líquido sobre la superficie de las hojas explica que se haya favorecido el arrastre de suciedad e insectos, tanto en el producto en rollos como en hojas sueltas, lo cual sugiere que facilitó que el agua de lavado penetrara al centro del producto, haciendo que el lavado fuera más eficaz. Complementario a estos resultados, la Figura 4b muestra los resultados de insectos recuperados de las hojas de los mismos grupos de productos de la Figura 4a, después del lavado, para producto con y sin sacudir. En todos los casos, los insectos detectados en las hojas fueron menores que los del tratamiento testigo, que no fue lavado, lo cual se explica por los insectos removidos por el agua de lavado con y sin tensoactivo e indica que con el lavado se logra reducir la cantidad de insectos presentes en el producto. 


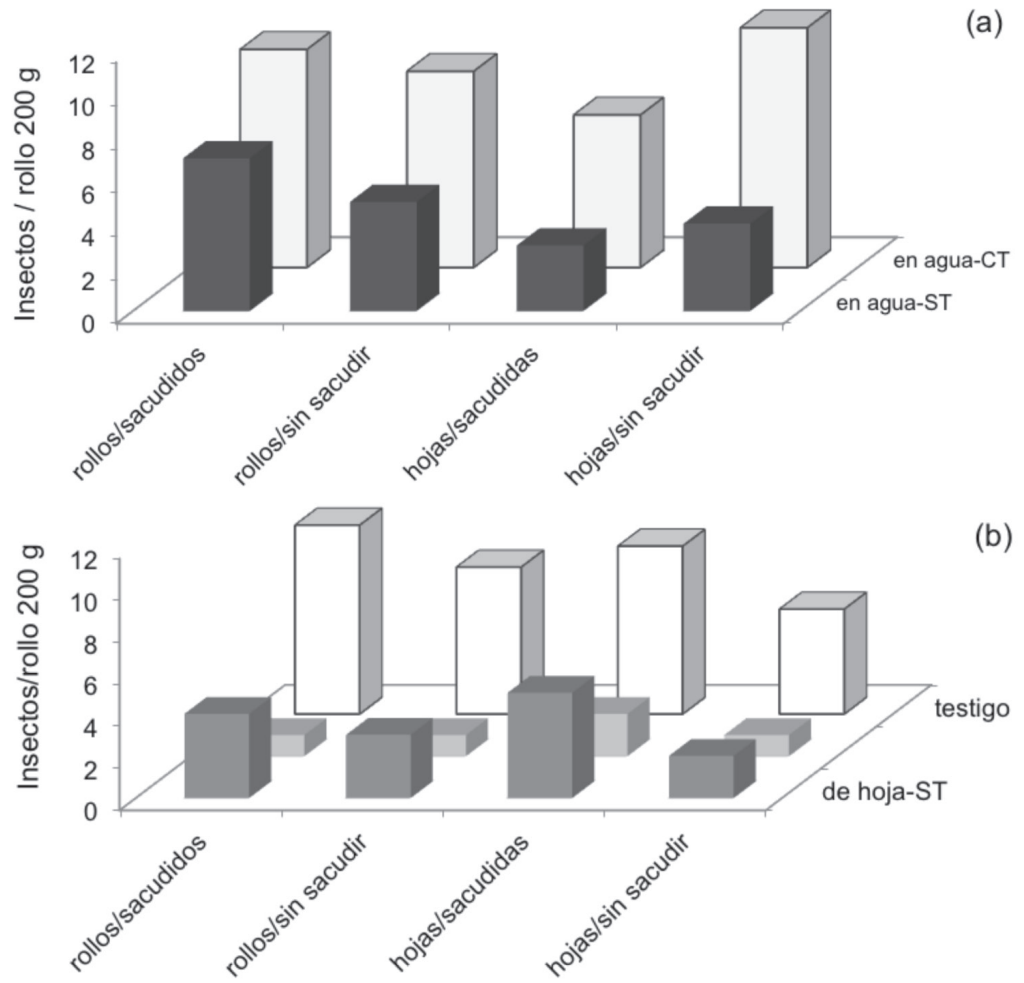

Rollo: manojo de hojas amarrado con banda de hule. Hojas sueltas: manojo de hojas sin amarrar.

Fig. 3. Insectos recuperados en el agua de lavado con y sin tensoactivo (a) y de la superficie de las hojas (b) de culantro coyote en rollos y hojas sueltas, con y sin sacudido.

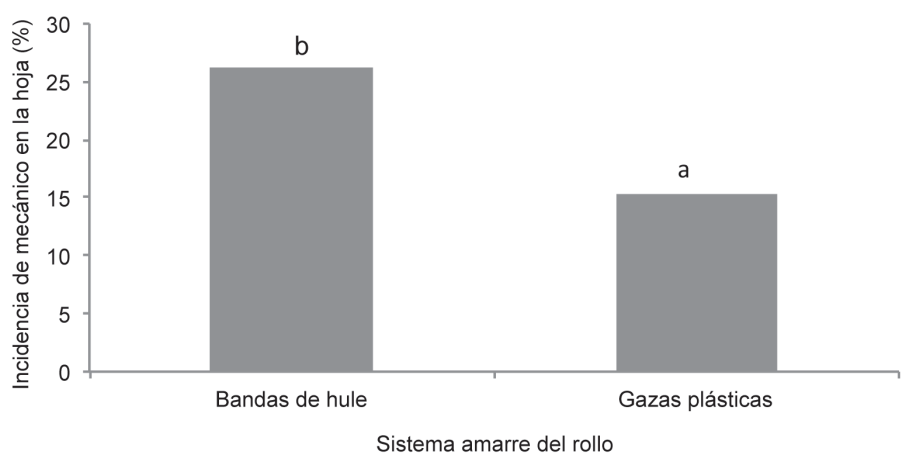

Medias de tratamientos con letras iguales no difieren entre sí según prueba DMS al 5\%.

Fig. 4. Efecto del uso de bandas de hule y gazas plásticas sobre la incidencia de daño mecánico en las hojas de culantro coyote.

Agronomía Costarricense 40(1): 51-64. ISSN:0377-9424 / 2016 
Después del lavado y sacudido de las hojas, también se extrajeron insectos de los mismos rollos y grupos de hojas sueltas, lo que evidencia que ninguno de los tratamientos fue $100 \%$ eficaz en remover la totalidad de insectos presentes en las hojas. La menor cantidad de insectos recuperados del culantro lavado con agua con tensoactivo, se atribuyó a una mayor eliminación de insectos durante el lavado, en contraste con los lavados con agua. Los resultados mostraron, que cuando los rollos u hojas sueltas se sacudían después del lavado, la recuperación de insectos de las hojas fue mayor, lo cual se atribuye a que la agitación rápida del producto, podría contribuir a separar los insectos de la superficie de las hojas.

Los resultados evidencian una alta presencia de insectos que no se logra controlar con el lavado y sacudido del producto. El uso de un tensoactivo en el agua de lavado y el sacudido contribuyen a eliminar la carga de insectos, pero en las dosis utilizadas no logran resolver el problema en su totalidad, lo que señala la necesidad de buscar alternativas para reducir la carga de insectos que vienen del campo y así como evaluar otras dosis de tensoactivo $u$ otros tratamientos que permitan una mayor eliminación de los residuos de insectos en el culantro coyote.

\section{Efecto del uso de gazas plásticas en la incidencia de daño mecánico en hojas de culantro coyote}

El amarre de los rollos de culantro con gazas plásticas permitió una reducción de un $11 \%$ en la incidencia de hojas con daños mecánicos (Figura 4) $(\mathrm{p} \leq 0,05)$, con respecto al uso de las bandas de hule, atribuido a la presión que ejercen éstas sobre las hojas que componen el rollo, por su elasticidad y por el área de contacto de éstas con las hojas de culantro. Las gazas se ajustan al tamaño del rollo y mantienen su forma y tamaño durante el almacenamiento, en contraste con las bandas de hule, que deben elongarse para introducir las hojas durante la preparación de los rollos y al liberarlas se mantienen tensas contra el producto, ejerciendo una presión permanente sobre el mismo durante todo el almacenamiento, al tratar de recuperar la forma y tamaño inicial del material. La tensión de la banda de hule, junto con la reducción de su diámetro, posiblemente incrementen los esfuerzos cortantes sobre las hojas y con ello mayores daños especialmente durante las operaciones poscosecha a que los rollos son sometidos, lo cual explica mayores quebraduras y cortes de las hojas en los puntos de contacto y proximidades. Se observó que al preparar los rollos, el uso de gazas también pueda dañar algunas hojas una vez colocadas pero estas no ejercen presión sobre las hojas ya que mantienen la forma y tamaño que se fija al formar el rollo, aspecto de mucha utilidad en este producto ya que como citan Cantwell y Reid (2002) los componentes de calidad de las hierbas frescas son en gran medida visuales entre otros, como la ausencia de defectos por daños mecánicos en las hojas.

Aunque los resultados mostraron una mejora en la reducción de la incidencia de hojas con daño mecánico al usar las gazas plásticas, no se logró controlar los daños, explicado en parte por la alta turgencia del producto durante los procesos de empaque, y la respuesta al sacudido, que somete el producto a esfuerzos de corte y tensión en lapsos de tiempo muy cortos. Sin embargo, se sugiere evaluar el uso de amarres alternativos de mayor grosor, para aumentar el área de contacto con el producto y reducir los esfuerzos cortantes, y con ello brindar mayor estabilidad al rollo durante el manejo ya que posteriormente a las operaciones de la planta de empaque, su manipulación es mínima.

\section{Efecto de las condiciones de almacenamiento sobre el amarillamiento, necrosis $y$ Cercospora sp., en hojas de culantro}

En la Figura 5 se observa que el amarillamiento ocurre a partir del día 7 en los rollos almacenados a 12 y $15^{\circ} \mathrm{C}$, alcanzando niveles de incidencia de más del $30 \%$ después de 12 días. En contraste, en el producto almacenado a $10^{\circ} \mathrm{C}$ se inhibió la expresión del color amarillo, por al menos 15 días de almacenamiento para el 

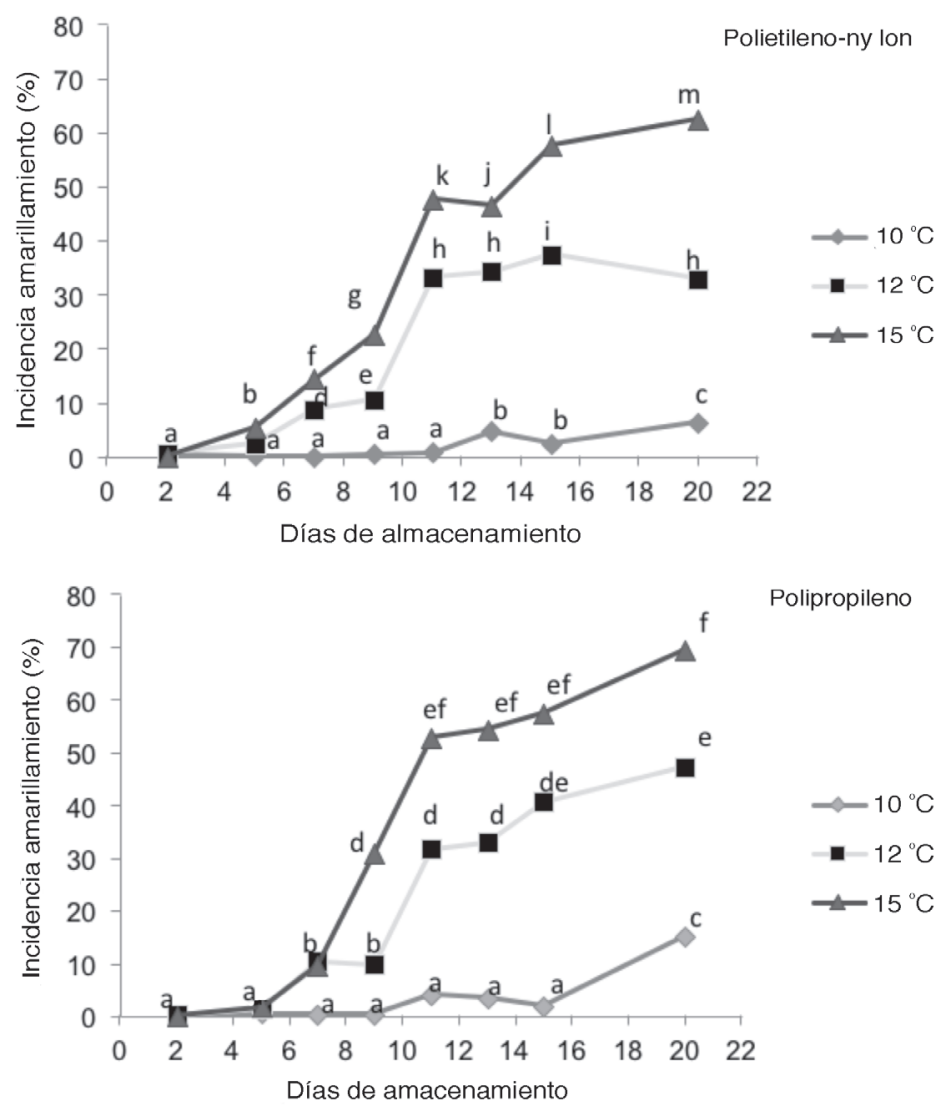

Medias de tratamientos con letras iguales no difieren entre sí según prueba DMS al 5\%.

Fig. 5. Efecto de la temperatura de almacenamiento y 2 diferentes empaques sobre la incidencia de amarillamiento en las hojas de culantro coyote.

producto empacado en bolsas de polipropileno y de polietileno+nylon.

Los resultados muestran que la temperatura tiene un mayor impacto que el empaque, el cual principalmente ayuda a que el producto se mantenga en un ambiente de alta humedad relativa, aunque también puede modificar la composición de la atmósfera interna. Aharoni et ál. (2007) señalan que el período de almacenamiento de las hierbas verdes frescas es reducido por su gran actividad metabólica expresada en parte por la acelerada senescencia foliar y la decadencia y que estos procesos se incrementan aún más después de la cosecha, manipulación y comercialización del producto, lo cual concuerda con los resultados, que muestran que el producto podría almacenarse por 15 días a $10^{\circ} \mathrm{C}$, sin que la incidencia de amarillamiento sea muy alta, pero a temperaturas mayores, el período de almacenamiento se reduce a 5 días, dado que según Namesny (1993), dicho proceso en las hojas a temperaturas altas se ve favorecido por la degradación de la clorofila, la cual es el pigmento predominante en estas hortalizas. Cantwell y Reid citados por Luo et ál. (2004) indican que el amarillamiento de las hojas y la 
deshidratación, entre otros, se encuentran entre los principales defectos que afectan la calidad de las hierbas durante el almacenamiento y al respecto la Norma Codex para Culantro coyote (CODEX STAN 304-R 2011) cita tolerancias de $5 \%$ de las hojas del rollo o manojo en el Culantro Categoría I y $15 \%$ de las hojas del rollo o manojo en el culantro coyote Categoría II para la variable amarillamiento, por lo que a $10^{\circ} \mathrm{C}$ el culantro calificaría como Categoría I hasta por 15 días.
Con respecto a la incidencia de necrosis en las hojas (Figura 6), la incidencia fue casi nula hasta el día 9 para el producto empacado en cualquiera de los 2 empaques, independientemente de la temperatura. A partir de ese día, la incidencia aumenta rápidamente para el producto almacenado a $15^{\circ} \mathrm{C}$, mientras que para $10 \mathrm{y}$ $12^{\circ} \mathrm{C}$ es casi nula hasta el día 13 ( 0 y $\left.0,5 \%\right)$, pero se incrementa en los siguientes días, para los 2 tipos de empaque, siendo más rápido el deterioro a 12 que a $10^{\circ} \mathrm{C}$.
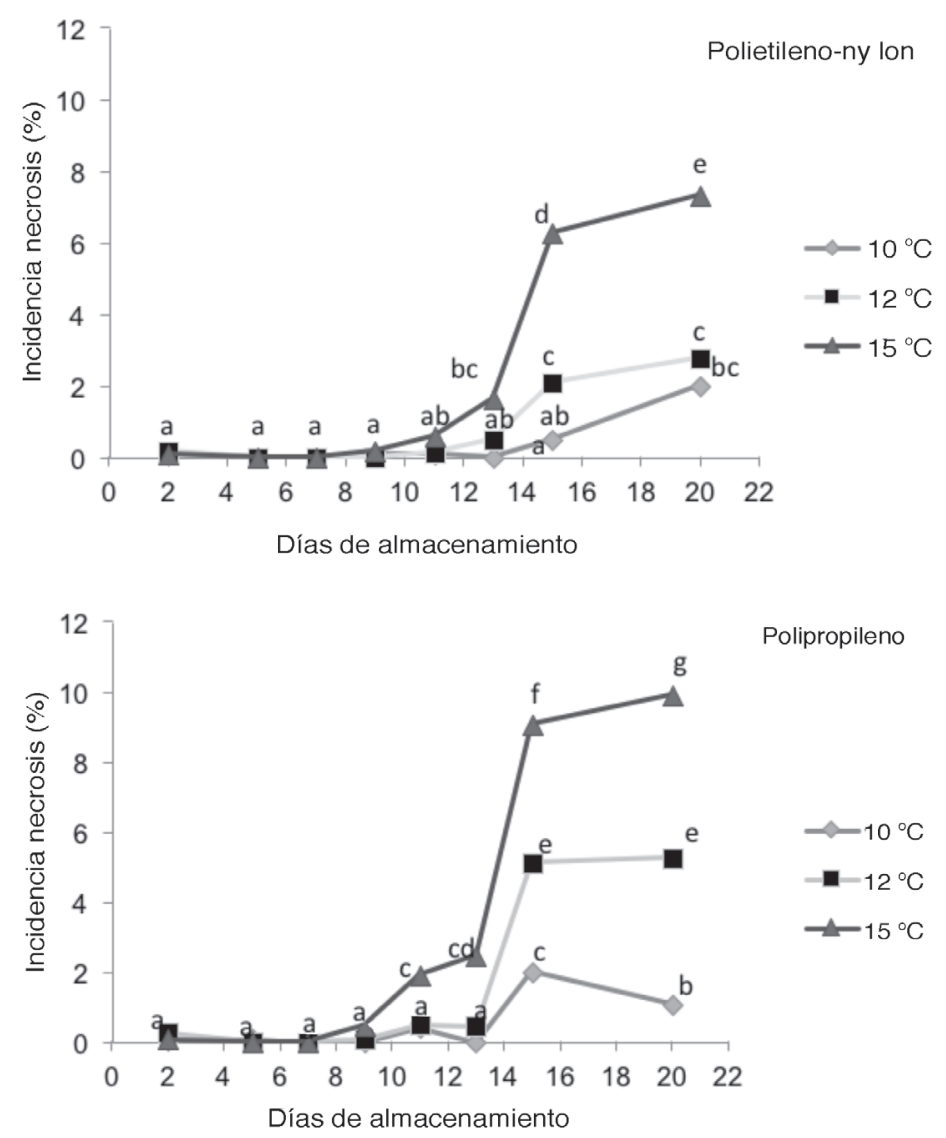

Medias de tratamientos con letras iguales no difieren entre sí según prueba DMS al 5\%.

Fig. 6. Efecto de la temperatura de almacenamiento y 2 diferentes empaques sobre la incidencia de necrosis en las hojas de culantro coyote. 
Para el empaque de polipropileno, la incidencia de necrosis fue ligeramente más pronunciada, lo cual pudo deberse a la composición de la atmósfera dentro del empaque, sin embargo, el efecto de la temperatura tuvo un efecto mucho mayor. La necrosis también se asocia a la senescencia de las hojas, por lo que la recomendación es el almacenamiento a $10^{\circ} \mathrm{C}$, para reducir la actividad metabólica del producto y extender su vida útil. En las Normas Codex para hortalizas, no existe a la fecha tolerancia para podredumbre, podredumbre blanda o descomposición interna, por lo que la nueva propuesta del Modelo General de Normas Codex de Frutas y Hortalizas de la FAO (2015), propone tolerancias para esas variables de $1 \%$ en producto de Categoría Extra y $3 \%$ para Categoría I. Según la anterior propuesta, los resultados de este ensayo indican que el producto se podría almacenar hasta por 20 días en el empaque de polietileno-nylon a $10^{\circ} \mathrm{C}$ y a $12^{\circ} \mathrm{C}$ ya que los valores de necrosis $(1,98 \%$ y $2,75 \%$ respectivamente) se encuentran dentro de los límites para ser clasificado como producto para Categoría I (3\%) pero no para la Categoria Extra $(1 \%)$, mientras que con el empaque de polipropileno se alcanzan esas categorías y ese período de almacenamiento pero solo a $10^{\circ} \mathrm{C}(1,08 \%)$.

La Figura 7 muestra resultados de la incidencia de daños por Cercospora menor al 5\% para todos los tratamientos. Durante los primeros
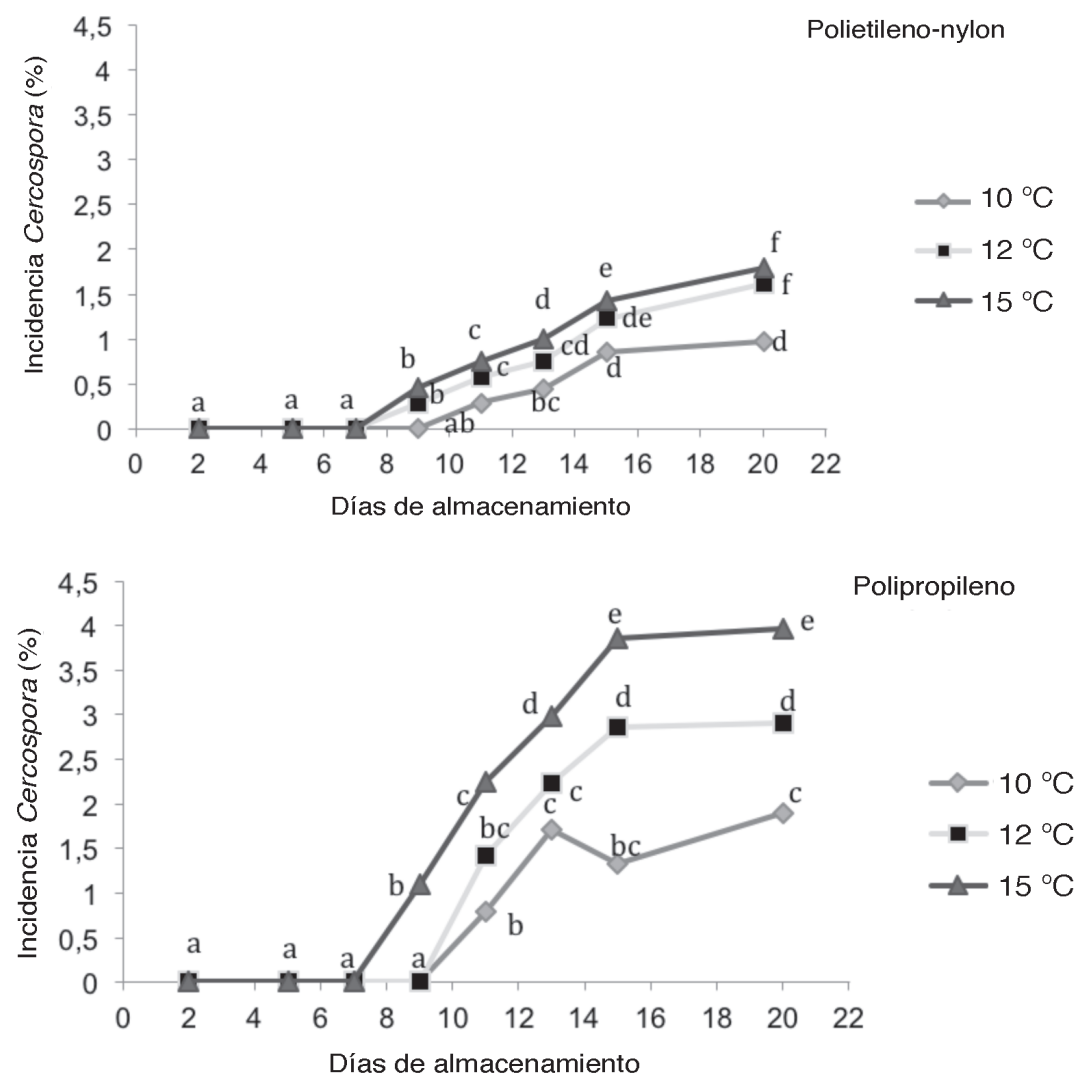

Medias de tratamientos con letras iguales no difieren entre sí según prueba DMS al 5\%.

Empaque $\mathbf{a}=$ polietileno+nylon, Empaque $\mathbf{b}=$ polipropileno.

Fig. 7. Efecto de la temperatura de almacenamiento y 2 diferentes empaques sobre la incidencia de Cercospora en las hojas de culantro coyote. 
9 días de almacenamiento, no se encontraron síntomas de Cercospora para el producto almacenado a $10^{\circ} \mathrm{C}$. No obstante, sí aumentó el número de hojas afectado por este hongo, especialmente en el producto empacado en bolsas de polipropileno, donde la incidencia duplicó la observada para el producto en bosas de polietileno-nylon, atribuido a diferencias en la atmósfera interna de los empaques.

En este caso y según lo expuesto sobre Normas Codex, se obtuvo que con el empaque de polietileno-nylon el producto clasifica como Categoría Extra hasta el día 20 a $10^{\circ} \mathrm{C}(0,97 \%)$ y como Categoría I a $12^{\circ} \mathrm{C}$ y a $15^{\circ} \mathrm{C}(1,62 \%$ y $1,79 \%$ respectivamente), mientras que en el empaque de polipropileno se clasifican como Categoría I hasta los 20 días pero a $10^{\circ} \mathrm{C}$ y $12^{\circ} \mathrm{C}$ $\left(1,89 \%\right.$ y $2,91 \%$ respectivamente) no así a $15^{\circ} \mathrm{C}$. Los resultados de este ensayo señalan como temperatura óptima de almacenamiento $10^{\circ} \mathrm{C}$ con cualquiera de los 2 empaques evaluados con ligeros beneficios adicionales al utilizar bolsas de polietileno-nylon, sin embargo a la luz de los costos hay que considerar el precio del empaque ya que el de polipropileno tiene un precio inferior con respecto al polietileno-nylon.

\section{CONCLUSIONES}

El sacudido del culantro en la presentación de rollos con amarre favoreció más el daño mecánico en la lámina de la hoja que en la presentación de rollos con hojas sueltas e independientes del tipo de presentación, el producto sacudido presentó más daño mecánico.

La aplicación del tensoactivo (TA) VegaA-Kleen sobre el escurrido del agua de rollos de culantro, permitió que al inicio del escurrido se extrajera hasta un $30 \%$ más de agua que en el producto que se lavó solo con agua.

La evaluación de la inmersión en agua con TA permitió recuperar en el agua con TA 37 insectos/rollo mientras que cuando no se usó el TA se recuperaron 19 insectos/rollo. Cuando el producto se sacudió (independiente del tipo de presentación) permitió recuperar una mayor cantidad de insectos que cuando el producto no se sacudió (56 y 48 respectivamente).

El uso de una centrífuga manual permitió extraer en el primer minuto a 75 y $50 \mathrm{rpm}$ la mayoría del volumen de agua y los daños mecánicos fueron $15 \%$ y $20 \%$ más bajos con el uso de la misma.

El amarre de los rollos de culantro con gazas plásticas permitió obtener una reducción de hasta $11 \%$ en la incidencia de hojas con daño mecánico en comparación con el producido por las ligas de hule tradicionales.

La incidencia de hojas amarillentas fue baja en el producto almacenado hasta 15 días a $10^{\circ} \mathrm{C}$, pero los síntomas de necrosis y Cercospora limitan la vida útil del producto de calidad extra. El culantro almacenado en bolsas de polietilenonylon o polipropileno durante 12 a 14 días a $10^{\circ} \mathrm{C}$ mantiene la calidad extra y la calidad 1 hasta por 20 días a $10^{\circ} \mathrm{C}$.

\section{LITERATURA CITADA}

AHARONI N., RODOV V., FALLIK E., AFEK U., CHALUPOWICZ D., AHARON Z., MAURER D., ORENSTEIN J. 2007. Modified atmosphere packaging for vegetable crops using high-watervapor-permeable films, pp. 73-112. In: Ch.L. Wilson (ed.). Intelligent and active packaging for fruits and vegetables. CRC Press Taylor\&Francis Group.

ALVARADO C., VILLALOBOS J. 1999. El cultivo del culantro coyote (Eryngium foetidum L., APIACEA) para exportación. MAG, San José, C.R. 23 p.

CANTWELL M., REID M. 2002. Postharvest Handling Systems: Fresh Herbs, pp. 327-331. In: A. Kader (ed.). Postharvest Technology of Horticultural Crops. University of California.

CERDAS M.M. 2010. Documento técnico respaldo para elaborar Norma Codex de culantro coyote. Laboratorio Poscosecha, CIA, UCR. San José, C.R. 11 p.

CODEX STAN 304-R. 2011. Norma Regional de Codex para el culantro coyote. $4 \mathrm{p}$.

COLEGIO DE INGENIEROS AGRÓNOMOS. 2003. Del café al culantro coyote. Boletín Informativo $\mathrm{N}^{\circ} .40$. San José, Costa Rica. 8 p.

FAO. 2015. Propuesta Modelo General de Normas Codex de Frutas y Hortalizas. FAO, Roma. 22 p.

KAYS S. 1997. Postharvest physiology of perishable plant products. Exon Press, USA. 532 p. 
LUO Y., McEVOY J., WACHTEL M., GANG J., HUANG Y. 2004. Package Atmosphere Affects Postharvest Biology and Quality of Fresh-cut Cilantro Leaves. HortSciencie 39(3):567-570.

MACNAB A., SHERF A., SPRINGER J. 1983. Identifying diseases of vegetables. College of Agriculture, The Pennsylvania State University. 62 p.

MAG. 2012. Guía técnica para la inspección de culantro coyote (Erygium foetidum) para la exportación. Costa Rica. 29 p.
MOHAMMED M., WICKMAN L. 1995. Postharvest retardation of senescence in shado benni (Eryngium foetidum). Journal of Foood Quality 18(4):325-334.

NAMESNY A. 1993. Post-recolección de hortalizas. Ediciones de Horticultura, S.L. Barcelona. 330 p.

SUBGGAK R., KULKARNI P. 1998. Leafy Vegetables, pp. 533-588. In: D. SALUNKHE and S. KADAM (eds.). Handbook of Vegetable Science and Technology. Marcel Dekker, Inc. 